\title{
Exercise alone and exercise combined with education both prevent episodes of low back pain and related absenteeism: systematic review and network meta- analysis of randomised controlled trials (RCTs) aimed at preventing back pain
}

\author{
Rongzhong Huang ${ }^{1,2}$ Jie Ning, ${ }^{1}$ Vivienne $\mathrm{H}_{\text {Chuter, }}{ }^{3}$ Jeffrey Bruce Taylor ${ }^{4}$, ${ }^{4,5}$ \\ Demoulin Christophe, ${ }_{1}^{6}$ Zengdong Meng, ${ }^{7} \mathrm{Yu} \mathrm{Xu}^{8}$ Lihong Jiang (1) ${ }^{1}$
}

- Additional material is published online only. To view please visit the journal online (http://dx.doi.org/10.1136/ bjsports-2018-100035).

For numbered affiliations see end of article.

Correspondence to Dr Lihong Jiang, The First People's Hospital of YunNan Province, Kunming 650000, China;

lihong-jiang@hotmail.com

Accepted 18 September 2019 Published Online First 31 October 2019

\section{ABSTRACT}

Objectives We aimed to investigate which prevention strategies for low back pain (LBP) are most effective. Design We completed a Bayesian network metaanalysis to summarise the comparative effectiveness of LBP prevention strategies. The primary outcomes were an episode of LBP and LBP-associated work absenteeism represented as ORs with associated $95 \%$ credibility intervals (Crls). We ranked all prevention strategies with surface under the cumulative ranking curve (SUCRA) analysis.

Data sources PubMed, EMBASE and CENTRAL databases were searched along with manual searches of retrieved articles. We only included randomised controlled trials (RCTs) that reported an episode of LBP and/or LBP-associated work absenteeism evaluating LBP prevention strategies were included.

Eligibility criteria for selecting studies Data were independently extracted by two investigators, and RCT quality was assessed using the Cochrane Risk of Bias tool.

Results and summary Forty RCTs were included. Exercise combined with education (OR: 0.59, Crl: 0.41 to 0.82 ) and exercise alone (OR: $0.59, \mathrm{Crl}: 0.36$ to 0.92 ) both prevented LBP episodes; exercise combined with education and education alone both had large areas under the curve (SUCRA: 81.3 and 79.4, respectively). Additionally, exercise (OR: 0.04, Crl: 0.00 to 0.34 ) prevented LBP-associated work absenteeism, with exercise and the combination of exercise and education ranking highest (SUCRA: 99.0 and 60.2, respectively). Conclusions Exercise alone and exercise combined with education can prevent episodes of LBP and LBPrelated absenteeism.

Trial registration number PROSPERO 42017056884.

\section{INTRODUCTION}

Low back pain (lower back pain, LBP) causes more disability globally than any other condition. ${ }^{1}$ Patients with chronic LBP experience debilitating pain, decreasing their quality of life. The economic costs associated with LBP are high due to productivity losses, work absenteeism, loss of personal income, increased disability, early retirement and increased medical resource use. ${ }^{23}$ LBP is caused by the interaction of various physical, anatomical, occupational, behavioural and psychosocial variables. Modifiable risk factors include physical activity/sedentary lifestyle, obesity, occupational exposures and psychosocial predictors such as depression and anxiety. ${ }^{45}$ Non-modifiable risk factors include sex (female) and age (older individuals). ${ }^{4-7}$ Therefore, practical interventions could have a significant impact on mitigating the burden of LBP.

Current LBP prevention strategies include back education, ergonomic adjustments, exercise, back belts and shoe insoles. Conventional systematic reviews and meta-analyses have evaluated the effectiveness of individual treatment approaches for the prevention of LBP against placebo or no intervention. ${ }^{8-19}$ However, it remains unclear which interventions are the most effective for LBP prevention and how these LBP prevention strategies rank relative to one another. The aim of this review was to systematically evaluate the relative effectiveness of primary LBP prevention strategies via Bayesian network meta-analysis.

\section{METHODS}

Data sources and searches

This study followed the guidelines detailed in the Preferred Reporting Items for Systematic Reviews and Meta-Analyses (PRISMA) Extension Statement for systematic reviews incorporating network meta-analyses. ${ }^{20}$ An extensive search of MEDLINE, EMBASE and CENTRAL databases from inception to 24 November 2017 was undertaken using the following key search terms: (low back pain OR lower back pain) AND prevent* AND random* AND control*. The reference lists cited in relevant systematic reviews and included trials were also screened. The searches were independently completed by two investigators (JL and ZM).

Inclusion and exclusion criteria

Inclusion criteria were as follows: (i) randomised controlled trials (RCTs) reporting (ii) a measure of a new episode of LBP or work absenteeism due to LBP that compared (iii) an eligible preventative intervention strategy for LBP. Participants within the study must have been without LBP at baseline or for those with previous or mild LBP, able to work/carry out normal activities. Eligible control and prevention 
strategies included: (i) standard care/no intervention and any single or combination of (ii) back education, (iii) exercise programme, (iv) back belt use, (v) shoe insole use and (vi) ergonomic adjustments (descriptions of all included interventions can be found in online supplementary appendix table B2). Standard/conventional care was reported and defined by the original study authors and included descriptors such as standard/usual care, no intervention, normal activity, routinely performed military exercises, ergonomic advice and video-training control. The treatment category 'standard/usual care' was often ambiguous and may have included some interventions as cointerventions (eg, standard military exercises with didactic training). As these minor interventions were previously deemed ineffective ${ }^{9} 11$ and are considered standard/usual care in their respective studies, they were analysed in that category. Studies had to be published in a peer-reviewed English language journal or have been included in a previous English language systematic review or meta-analysis.

We excluded non-RCTs, studies focused on pregnant women, and studies focused on participants in specific occupations that would be difficult to generalise to the general LBP patient population (eg, workers exposed to high levels of vibration).

\section{Study selection}

Two investigators (JL and ZM) independently screened all initial search results. Duplicates and articles not meeting the selection criteria based on title and abstract were removed. Full-text articles of all remaining studies were then independently screened by two investigators (JL and JN) for inclusion. Disagreements regarding inclusion were resolved by discussion and consensus.

\section{Outcome measures}

The prespecified primary outcome was incidence of LBP as measured by the proportion of participants who reported an episode of LBP at follow-up, reported as an OR and the associated $95 \%$ credibility interval (CrI). The prespecified secondary outcome was work absenteeism associated with LBP as measured by the proportion of participants reporting a work absence due to LBP, reported as an OR and the associated 95\% CrI. Additional summary measures include treatment rankings based on the surface under the cumulative ranking (SUCRA) scores. The SUCRA provides a statistically-based overall ranking associated with a particular intervention; SUCRA values can range from 0 to 100 , with higher SUCRA values indicating a greater likelihood that a therapy is superior. ${ }^{21}$

\section{Data extraction and quality assessment}

Two investigators (JL and RH) independently extracted data from the included RCTs using a standardised data extraction form. In the event of disagreement, rechecking of the original article followed by discussion between the two coauthors was used to reach a consensus. The following data parameters were extracted from each RCT: name of the primary author, country of study, trial design, number of participants in each study arm, characteristics of the intervention (eg, schedule, dosage and/or duration of intervention), patient diagnosis, patient age (mean or median), patient sex (male \%), follow-up duration, outcome type (incidence of LBP or episode of work absence due to LBP) and outcomes at longest follow-up point. When needed, dispersion effects were approximated from the figures provided. Intentionto-treat data were used when available.

\section{Assessment of risk of bias}

The methodological quality of included RCTs was assessed using the Cochrane Collaboration's Risk of Bias approach. ${ }^{22}$ Two investigators (JN and JL) independently performed the risk-ofbias assessment on the included RCTs. In the event of disagreement, rechecking of the original article followed by discussion between the two coauthors was used to reach a consensus.

\section{Data synthesis and analysis}

A Bayesian random effect model of network meta-analysis was used to compare the overall effect size among interventions to account for differences among trials for the outcomes of an episode of LBP and work absence. Network meta-analysis enables an integration of all available direct and indirect evidence across multiple trials to compare interventions. ${ }^{23}$ Network metaanalysis can increase the statistical power and also examine the relative effects of different interventions that have few comparisons or have never been compared directly. Network metaanalysis presumes transitivity, which means that one can evaluate treatment A versus treatment $\mathrm{B}$ via a third intermediary treatment C. ${ }^{24}$ Therefore, we assumed that the participants within the included studies were randomly allocated to the various treatments being compared; in other words, we assumed no bias in participant randomisation. This is a reasonable assumption considering that all studies included within this network metaanalysis were RCTs.

Analyses were done using Markov chain Monte Carlo methods. The network meta-analysis was conducted using WinBUGS V.1.4.3 (MRC Biostatistics Unit, Cambridge, UK). The WinBUGS codes are available in online supplementary appendix G. The network ORs were calculated from the median of the posterior distribution and 95\% CrIs. We chose minimally informative prior distributions for all variables. For each outcome, we summarised the evidence using a network diagram. We assessed the achievement of convergence by the Brooks-Gelman-Rubin statistic. We calculated the SUCRA rankings as well as the probability of being best (PrBest) for each intervention.

To check the robustness of the network meta-analysis, we performed a pairwise random-effects meta-analysis for all available direct comparisons using Stata (release 12, Stata, College Station, Texas, USA). ${ }^{25}$ The goodness-of-fit of the models to the data was assessed by: (i) tabulation of the residual deviance; (ii) visual inspection of the residual distributions on Q-Q plots; (iii) calculation of treatment effect heterogeneity from the posterior median of $\tau 2$ (between-trial variance) and (iv) calculation of network consistency through the difference in effect sizes between indirect and direct comparisons. For each model, we generated 100000 simulations after discarding the first 50000 simulations as burn-in. For pairwise meta-analyses, heterogeneity among studies was evaluated using the $I^{2}$ statistic $\left(\mathrm{p}<0.10\right.$ and $I^{2}>50 \%$ indicating evidence of heterogeneity), ${ }^{26}$ and Egger's test was employed to investigate small-study effects (ie, the tendency for smaller studies to show disproportionately larger treatment effects ${ }^{27}$ ) if at least four trials were included in a particular comparison.

\section{Role of the funding source}

The funders had no role in study design, data collection and analysis, decision to publish or preparation of the manuscript.

\section{RESULTS}

\section{Included studies}

The PRISMA flow diagram describing the study selection process is presented in online supplementary appendix A. The initial database searches and reference checks resulted in a total 978 records, of which 277 were appropriate for fulltext review. A total of 40 studies were finally included in this 
network meta-analysis. Of these, 38 studies $^{28-65}$ reporting 46 RCTs (accounting individually for multiple study arms within trials) were included in the Episode of LBP network (see online supplementary appendix tables B1 and B2 for descriptions and baseline data of included studies, respectively). Four of these 38 studies included three study arms. ${ }^{36445960}$ In addition, 13 studies $^{32} 38434853$ 56-6066 67 reporting 17 RCTs were included in the Episode of Work Absence network. All included studies were published between 1990 and 2016. Most of the included studies focused largely or completely on working-age populations. Follow-up periods ranged from 1 week to 4 years.

\section{Risk of bias}

We have presented the Risk of Bias assessment in online supplementary appendix table B3. Of the 40 total studies, 3 studies $(7.5 \%)$ were considered to have a low risk of bias (>9 bias score)..$^{52} 5355$ Twenty studies (50\%) were considered to present a moderate risk of bias. ${ }^{28} 31323439-4246495057-5961-6568$ The remaining seventeen studies $(42.5 \%)$ were considered to have a high or unclear risk of bias (<6 bias score). ${ }^{29303335-3843-4547485154606667}$ Of the 40 studies, 32 studies $(80 \%)$ used adequate randomisation and 11 studies (30\%) used adequate allocation concealment. Only six studies $(15 \%)$ clearly described the blinding process of the participants, while 29 studies $(72.5 \%)$ did not blind participants, providers or outcome assessors or did not report on blinding. Twenty-five studies $(62.5 \%)$ reported a low dropout rate $(<20 \%)$. Most studies did not evaluate or report on compliance with the interventional protocol. Thirty-one studies $(77.5 \%)$ were registered in an accessible clinical trial registry or reported on all stated outcomes and time-points. Twenty-eight studies (70\%) reported a comparative analysis confirming similarity of baseline data.

\section{Effects of interventions}

Figure 1 shows the network plots detailing the treatment comparisons for Episode of LBP and Episode of Work Absence analyses.

\section{Episode of LBP analysis}

A summary of findings for the Episode of LBP analysis can be found in online supplementary appendix table B4 and the forest plot of ORs and 95\% CrI is reported in figure 2. Summary effect estimates for the comparison of each intervention strategy with standard care are presented in figure 3 and online supplementary appendix table $\mathrm{C} 1$. Of the forty-six comparisons included in the Episode of LBP network, significant outcomes favouring the intervention over standard care included exercise (OR: 0.59, a)

Treatments

Odds Ratio $95 \% \mathrm{CrI}$

Exercise + Ergonomic Adjustments (H)

Education + Ergonomic Adjustments (G)

Ergonomic Adjustments ( $F$ )

Education (A)

Back Belt (D)

Shoe Insoles ( $E$ )

Exercise (B)

Exercise + Educ ation ( $C$
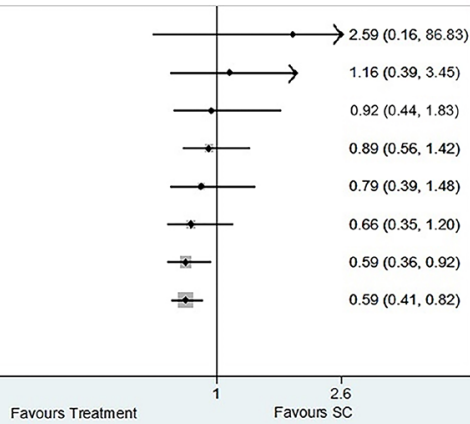

b)

Treatments

Odds Ratio

(a)

Back Belt (D)

Education + Ergonomic Adjustments (G)

Education (A)

Exercise + Ergonomic Adjustments (H)

Exercise + Education $(C)$

Exercise (B)

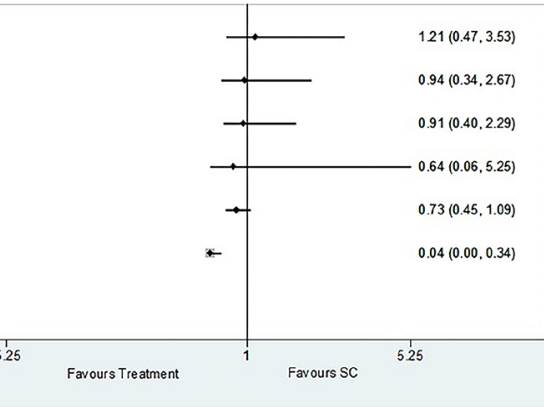

Figure 2 Forest plots of outcomes. Forest plots comparing prevention strategies for (a) episode of LBP and (b) LBP-related work absence. Diamonds illustrate the summary effect sizes. Error bars indicate $95 \%$ Crl. LBP, low back pain.

CrI: 0.36 to 0.92 ) and exercise+education (OR: 0.59, CrI: 0.41 to 0.82 ). The SUCRA values are found in online supplementary appendix table C1, while the rankogram of SUCRA values is reported in online supplementary appendix figure $\mathrm{C} 1$. The two interventions with the highest SUCRA values were exercise+education (81.3) and exercise (79.4). The complete league table

B

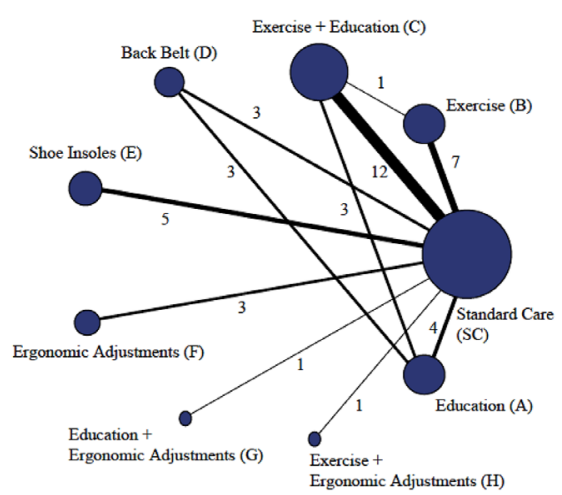

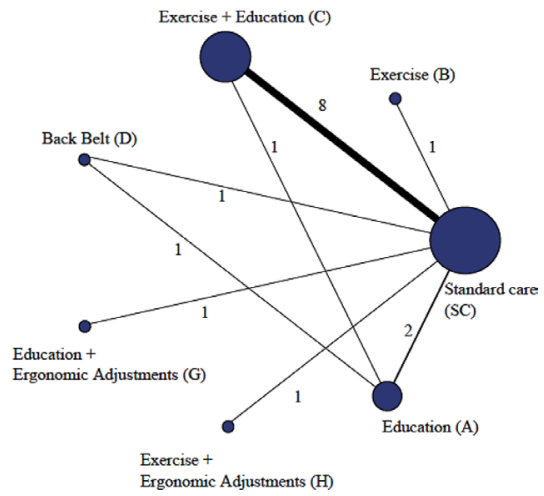

Figure 1 Network plots of outcomes. Network plots comparing prevention strategies for (a) episode of LBP and (b) LBP-related work absence. Size of nodes is proportional to the number of patients randomised to interventions. Thickness of lines is proportional to the number of studies contributing to the direct comparison. LBP, low back pain. 


\begin{tabular}{|l|l|l|l|l|l|l|l|l|}
\hline & $\begin{array}{l}\text { Standard Care } \\
\text { (SC) }\end{array}$ & Exercise (B) & $\begin{array}{l}\text { Exercise + } \\
\text { Education (C) }\end{array}$ & Back Belt (D) & Shoe Insoles (E) & $\begin{array}{l}\text { Ergonomic } \\
\text { Adjustments (F) }\end{array}$ & $\begin{array}{l}\text { Education + } \\
\text { Ergonomic } \\
\text { Adjustments (G) }\end{array}$ & $\begin{array}{l}\text { Exercise + } \\
\text { Ergonomic } \\
\text { Adjustments (H) }\end{array}$ \\
\hline Education (A)
\end{tabular}

Figure 3 League tables for episode of LBP. ORs for the column intervention versus the row intervention are shown above the diagonal. Reciprocal ORs for the row intervention versus the column intervention are shown below the diagonal. ORs of less than unity indicate that the column intervention is favoured over the row intervention. Significant relative effects between a pair of interventions are reported in bold font. LBP, low back pain.

of effect estimates for the Episode of LBP analysis is reported in online supplementary appendix Table D1.

\section{Episode of Work Absence analysis}

Summary effect estimates against standard care for the Episode of Work Absence analysis are presented in figure 4 and online supplementary appendix table C2. A summary of findings can be found in the Appendix Table B5 and the forest plot of ORs and $95 \% \mathrm{CrI}$ are reported in figure 2 . Of the $17 \mathrm{RCT}$ that were compared in the Episode of Work Absence analysis, only exercise reached significance. Other significant findings included exercise as significantly effective as compared against exercise + education (OR: 0.06, CrI: 0.00 to 0.50 ), back belt (OR: 0.03 , CrI: 0.00 to 0.33), education+ergonomic adjustments (OR: 0.04, CrI: 0.45) and education (OR: $0.05, \mathrm{CrI}: 0.00$ to 0.42 ). The SUCRA values are found in online supplementary appendix table C2, while the rankogram of SUCRA values for Episode of Work Absence is reported in online supplementary appendix figure C2. The interventions with the highest SUCRA value were exercise (99.0) and exercise+education (60.2). The complete league table of effect estimates for the Episode of Work Absence analysis is reported in online supplementary appendix table D2.

Between study heterogeneity, model fit and comparison with standard pairwise meta-analyses

The observed values for $I^{2}$ from the network meta-analyses are presented in Appendix online supplementary appendix table $\mathrm{C} 1$ and $\mathrm{C} 2$. The between study heterogeneity results showed that, for pairwise comparisons against standard care, there was a low-to-moderate level of heterogeneity in the Episode of LBP network with interventions as low as $0 \%$ to as high as $85 \%$ in the exercise group. The presence of heterogeneity in the Episode of Work Absence network was $0 \%$ for all $I^{2}$ statistics comparisons.

The autocorrelation and history plots for both networks showed good convergence. The goodness-of-fit of the models to the data as measured by the residual deviance showed good fit for both networks (online supplementary appendix table E1). The comparison of heterogeneity results from the network meta-analyses (online supplementary appendix table C1 and C2) with those of the random effects pairwise meta-analyses (online supplementary appendix tables E2 and E3) mostly showed agreement. No indication of small-study effects was observed in either network analysis as reported in online supplementary appendix F.

\section{DISCUSSION}

Our study confirmed the use of exercise alone, as well as exercise combined with education, as effective prevention strategies for LBP. It is the first network meta-analysis to include all researched interventional strategies for the prevention of an episode of LBP and LBP-related work absenteeism. The advantages of network meta-analyses are that they can simultaneously compare more than two treatments, provide relative effect estimates for all treatment comparisons, enable the estimation of PrBest and reduce the uncertainty in treatment effect estimates.

Previous reviews of LBP interventions have found minimal evidence supporting the effectiveness of education, ${ }^{9} 1117186970$ back belts, ${ }^{916-1871}$ shoe insoles, ${ }^{891213}$ or ergonomic adjustments. ${ }^{15}$ Some reviews found evidence supporting the efficacy of exercise for preventing an episode of LBP and/or LBP-related work absenteeism. ${ }^{91718697273}$ Similar to the reviews that reported the efficacy

\begin{tabular}{|c|c|c|c|c|c|c|c|}
\hline & Standard Care (SC) & Exercise (B) & $\begin{array}{l}\text { Exercise + } \\
\text { Education (C) }\end{array}$ & Back Belt (D) & $\begin{array}{l}\text { Education + } \\
\text { Ergonomic } \\
\text { Adjustments (G) }\end{array}$ & $\begin{array}{l}\text { Exercise + } \\
\text { Ergonomic } \\
\text { Adjustments (H) }\end{array}$ & Education (A) \\
\hline Standard Care (SC) & SC & $0.04(0.0 ; 0.34)$ & $0.73(0.45 ; 1.09)$ & $1.21(0.47 ; 3.53)$ & $0.94(0.34 ; 2.67)$ & $0.64(0.06 ; 5.25)$ & $0.91(0.4 ; 2.29)$ \\
\hline Exercise (B) & $24.24(2.98 ; 1023.66)$ & B & $17.68(1.99 ; 744.66)$ & 28.71(3.0;1368.99) & $\begin{array}{l}22.49(2.24 ; 1068.68 \\
\text { l }\end{array}$ & $16.53(0.6 ; 997.87)$ & $22.0(2.38 ; 913.43)$ \\
\hline Exercise + Education (C) & $1.37(0.92 ; 2.22)$ & $0.06(0.0 ; 0.5)$ & C & $1.66(0.61 ; 5.51)$ & $1.29(0.45 ; 4.16)$ & $0.89(0.08 ; 7.62)$ & $1.25(0.52 ; 3.6)$ \\
\hline Back Belt (D) & $0.83(0.28 ; 2.15)$ & $0.03(0.0 ; 0.33)$ & $0.6(0.18 ; 1.64)$ & D & $0.77(0.18 ; 3.16)$ & $0.52(0.04 ; 5.35)$ & $0.75(0.27 ; 2.17)$ \\
\hline $\begin{array}{l}\text { Education + Ergonomic } \\
\text { Adjustments (G) }\end{array}$ & $1.07(0.38 ; 2.94)$ & $0.04(0.0 ; 0.45)$ & $0.78(0.24 ; 2.24)$ & $1.3(0.32 ; 5.65)$ & G & $0.69(0.05 ; 6.98)$ & $0.96(0.27 ; 3.91)$ \\
\hline $\begin{array}{l}\text { Exercise + Ergonomic } \\
\text { Adjustments }(\mathrm{H})\end{array}$ & $1.56(0.19 ; 16.93)$ & $0.06(0.0 ; 1.67)$ & $1.13(0.13 ; 12.59)$ & $1.93(0.19 ; 26.03)$ & $1.45(0.14 ; 20.91)$ & $\mathbf{H}$ & $1.46(0.15 ; 18.32)$ \\
\hline Education (A) & $1.1(0.44 ; 2.53)$ & $0.05(0.0 ; 0.42)$ & $0.8(0.28 ; 1.91)$ & $1.34(0.46 ; 3.68)$ & $1.04(0.26 ; 3.66)$ & $0.68(0.05 ; 6.62)$ & A \\
\hline
\end{tabular}

Figure 4 League tables for work absence due to LBP. ORs for the column intervention versus the row intervention are shown above the diagonal. Reciprocal ORs for the row intervention versus the column intervention are shown below the diagonal. ORs of less than unity indicate that the column intervention is favoured over the row intervention. Significant relative effects between a pair of interventions are reported in bold font. 
of exercise, our network meta-analyses reported significant effects favouring exercise as well as the combination of exercise education interventions. Our current analysis includes 40 studies, since newly published reports have been identified since the last-published review of low back pain prevention strategies, ${ }^{74}$ which included 21 RCTs and only compared interventions against no intervention or placebo. Moreover, previous meta-analyses have been limited by their inability to include reports on head-to-head comparisons, diminishing the number of eligible studies.

There are several limitations to this study. First, although a previous systematic review reported no significant differences in effect for shorter and longer (>12 months) follow-up periods, ${ }^{73}$ pooling of various follow-up periods in our analysis may have diluted the minor positive short-term benefits of exercise. Variability in the actual exercise regimens employed within the pooled studies in this analysis may also have weakened the true effects of exercise intervention. As our exercise programme may reduce the risk of first-time and recurrent LBP, we recommend further investigation to even better characterise the elements of exercise prescription (Frequency, Intensity, Type, Time) that best prevent LBP. Second, the random-effects network meta-analysis model relies on the assumption that the relative preventative effect of one strategy versus another is the same across the entire set of studies. Therefore, to address the question of which prevention intervention for LBP is most effective, we were primarily interested in the average effect of each intervention in order to account for the diversity within each intervention. To accomplish this, we had to pool studies that were heterogeneous with respect to intervention, study design and risk of bias. As a result, there was considerable $\left(I^{2}>75 \%\right)$ between-study heterogeneity present in some comparisons. Third, the small number of relevant studies within the networks for some comparisons means that the results for interventions such as (i) exercise combined with ergonomic adjustments and (ii) education combined with ergonomic adjustments, should be interpreted with caution. Fourth, the network meta-analyses were also based on a single timepoint (the longest follow-up point), which may be considered as a limitation due to varying follow-up periods.

\section{Implications for practice}

Exercise alone, as well as the combination of exercise with education, prevented episodes of LBP as well as LBP-associated work absenteeism. Other prevention strategies did not achieve statistical significance. Our finding that most LBP prevention strategies are ineffective is consistent with the findings of previous conventional reviews and meta-analyses. In addition, participant preference and cost-effectiveness should also be considered when implementing LBP prevention interventions and combining of prevention strategies should also be considered.

With regard to future clinical research in this field, researchers should focus on strengthening the evidence base within network arms of each prevention strategies to achieve statistical significance. Investigators also need to precisely define 'standard/usual care' within their respective studies, so it is easier for other researchers to appropriately categorise and pool studies. Investigators should focus on the effect of interventions across multiple follow-up time points, as strategies may vary in relative efficacy over time. Policy makers and administrators should focus on supporting further research as well as implementing and evaluating new prevention strategies which may prove more effective in preventing LBP.

\section{CONCLUSION}

Our Bayesian network meta-analysis provides support for exercise alone, as well as exercise combined with education, as
Key messages

- Low back pain (LBP) causes disability globally; however, it remains unclear which prevention strategies for LBP are most effective.

- Current prevention strategies include back education, ergonomic adjustments, exercise, back belts and shoe insoles.

- Our results support exercise and the combination of exercise and education as the most effective preventative measured for LBP.

effective prevention strategies for LBP. We recommend large higher-quality RCTs, including head-to-head comparisons of preventive interventions, to validate these results.

\section{Author affiliations}

${ }^{1}$ Department of Cardiothoracic Surgery, The First People's Hospital of YunNan Province, Kunming, China

${ }^{2}$ Department of Gerontology, The Second Affiliated Hospital of Chongqing Medical University, Chongqing, China

${ }^{3}$ School of Health Sciences, University of Newcastle, Ourimbah, New South Wales, Australia

${ }^{4}$ Physical Therapy, High Point University, High Point, North Carolina, USA ${ }^{5}$ Kinesiology, University of North Carolina at Greensboro, Greensboro, North Carolina, USA

${ }^{6}$ Department of Sport and Rehabilitation Sciences, University of Liege, Liege, Belgium ${ }^{7}$ Department of Orthopedics, First People's Hospital of YunNan Province, YunNan, China

${ }^{8}$ Statistical Laboratory, Chongqing Chuangxu Lifescience Institute, Chongqing, China

Twitter Jeffrey Bruce Taylor @jbtaylor_pt

Contributors RH, JN, YX and ZM screened titles and abstracts. VHC, JBT, DC, $Y X$ and RH performed methodological quality assessments and data extraction, methodological quality assessments and data analyses. RH, JN, VHC, JBT, DC and LJ wrote the initial draft of the manuscript and all review authors critically reviewed the manuscript.

Funding This work was supported by the National Natural Science Foundation of China (grant no. 31300137).

Competing interests None declared.

Patient consent for publication Not required.

Provenance and peer review Not commissioned; externally peer reviewed.

\section{ORCID iDs}

Jeffrey Bruce Taylor http://orcid.org/0000-0002-6608-0192

Lihong Jiang http://orcid.org/0000-0002-0366-2275

\section{REFERENCES}

1 Hoy D, March L, Brooks P, et al. The global burden of low back pain: estimates from the global burden of disease 2010 study. Ann Rheum Dis 2014;73:968-74.

2 Delitto A, George SZ, Van Dillen L, et al. Low back pain. J Orthop Sports Phys Ther 2012:42:A1-57.

3 Dagenais S. Caro J Fau - Haldeman S, Haldeman S. A systematic review of low back pain cost of illness studies in the United States and internationally. Spine J 2008;8:8-20.

4 Taylor JB, Goode AP, George SZ, et al. Incidence and risk factors for first-time incident low back pain: a systematic review and meta-analysis. The Spine Journal 2014;14:2299-319.

5 IbrahimiKacuri D, Murtezani A, Rrecaj S, et al. Low back pain and obesity. Med Arh 2015:69:114-6.

6 van Tulder M, Koes B, Bombardier C. Low back pain. Best Pract Res Clin Rheumatol 2002;16:761-75.

7 Hall H, Mclntosh G. Low back pain (chronic). BMJ Clin Evid 2008;2008.

8 Bonanno DR, Landorf KB, Munteanu SE, et al. Effectiveness of foot orthoses and shock-absorbing insoles for the prevention of injury: a systematic review and metaanalysis. Br J Sports Med 2017;51:86-96.

9 Steffens D, Maher CG, Pereira LSM, et al. Prevention of lowback pain a systematic review and meta-analysis. JAMA Int Med 2016;176:199-208. 
10 Moreira-Silva I, Teixeira PM, Santos R, et al. The effects of workplace physical activity programs on musculoskeletal pain: a systematic review and meta-analysis. Workplace Health Saf 2016;64:210-22.

11 Ainpradub K, Sitthipornvorakul E, Janwantanakul P, et al. Effect of education on nonspecific neck and low back pain: a meta-analysis of randomized controlled trials. Man Ther 2016;22:31-41.

12 Sahar T, Cohen MJ, Ne'eman V, et al. Insoles for prevention and treatment of back pain. Cochrane Database Syst Rev 2007;11.

13 Chuter V, Spink M, Searle A, et al. The effectiveness of shoe insoles for the prevention and treatment of low back pain: a systematic review and meta-analysis of randomised controlled trials. BMC Musculoskelet Disord 2014;15.

14 Demoulin C, Marty M, Genevay S, et al. Effectiveness of preventive back educational interventions for low back pain: a critical review of randomized controlled clinical trials. Eur Spine J 2012;21:2520-30.

15 Driessen MT, Proper KI, van Tulder MW, et al. The effectiveness of physical and organisational ergonomic interventions on low back pain and neck pain: a systematic review. Occup Environ Med 2010:67:277-85.

16 van Duijvenbode I, Jellema P, van Poppel M, et al. Lumbar supports for prevention and treatment of low back pain. Cochrane Database Syst Rev 2008:2.

17 van Poppel MNM, Hooftman WE, Koes BW. An update of a systematic review of controlled clinical trials on the primary prevention of back pain at the workplace. Occup Med 2004;54:345-52.

18 Maher CG. A systematic review of workplace interventions to prevent low back pain. Australian Journal of Physiotherapy 2000;46:259-69.

19 Lahad Aet al. The effectiveness of four interventions for the prevention of low back pain. JAMA 1994:272:1286-91.

20 Hutton B, Salanti G, Caldwell DM, et al. The PRISMA extension statement for reporting of systematic reviews incorporating network meta-analyses of health care interventions: checklist and explanations. Ann Intern Med 2015;162:777.

21 Rücker G, Schwarzer G. Ranking treatments in frequentist network meta-analysis works without resampling methods. BMC Med Res Methodo/ 2015;15:58

22 Higgins JPT, Altman DG, Gotzsche PC, et al. The Cochrane collaboration's tool for assessing risk of bias in randomised trials. BMJ 2011;343:d5928.

23 Mills EJ, Thorlund K, loannidis JPA. Demystifying trial networks and network metaanalysis. BMJ 2013:346:f2914.

24 Salanti G. Indirect and mixed-treatment comparison, network, or multiple-treatments meta-analysis: many names, many benefits, many concerns for the next generation evidence synthesis tool. Res. Syn. Meth. 2012;3:80-97.

25 Furlan AD, Pennick V, Bombardier C, et al. 2009 updated method guidelines for systematic reviews in the Cochrane back review group. Spine 2009;34:1929-41.

26 Higgins JPTet al. Measuring inconsistency in meta-analyses. BMJ 2003;327:557-60.

27 Sterne JAC, Harbord RM. Funnel plots in meta-analysis. Stata J 2004;4:127-41.

28 Alexandre NMC, Moraes MAAde, Corrêa Filho HR, et al. Evaluation of a program to reduce back pain in nursing personnel. Rev. Saúde Pública 2001;35:356-61.

29 Alexander A, Woolley S, Bisesi M, et al. The effectiveness of back belts on occupational back injuries and worker perception. Prof Safety 1995:22-6.

30 Allen SK, Wilder K. Back belts pay off for nurses. Occup Health Saf 1996;65:59-62

31 Brisson C, Montreuil S, Punnett L. Effects of an ergonomic training program on workers with video display units. Scand J Work Environ Health 1999;25:255-63.

32 Chal Ã@at-Valayer E, Denis AngÃ@lique, Abelin-Genevois K, et al. Long-Term effectiveness of an educational and physical intervention for preventing lowback pain recurrence: a randomized controlled trial. Scand J Work Environ Health 2016:42:510-9.

33 Cook C, Burgess-Limerick R. The effect of forearm support on musculoskeletal discomfort during call centre work. Appl Ergon 2004;35:337-42.

34 Fanucchi GL, Stewart A, Jordaan R, et al. Exercise reduces the intensity and prevalence of low back pain in 12-13 year old children: a randomised trial. Austr J Physiother 2009;55:97-104.10.1016/S0004-9514(09)70039-X

35 Faunø $\mathrm{P}$, Kålund $\mathrm{S}$, Andreasen I, et al. Soreness in lower extremities and back is reduced by use of shock absorbing heel inserts. Int J Sports Med 1993;14:288-90.

36 George SZ, Childs JD, Teyhen DS, et al. Brief psychosocial education, not core stabilization, reduced incidence of low back pain: results from the prevention of low back pain in the military (POLM) cluster randomized trial. BMC Med 2011:9:128.

37 Gerdle B, Brulin C, Elert J, et al. Effect of a general fitness program on musculoskeletal symptoms, clinical status, physiological capacity, and perceived work environment among home care service personnel. J Occup Rehabil 1995;5:1-16.

38 Glomsrød B, Lønn JH, Soukup MG, et al. "Active back school", prophylactic management for low back pain: three-year follow-up of a randomized, controlled trial. J Rehabil Med 2001;33.

39 Haukka E, Leino-Arjas P, Viikari-Juntura E, et al. A randomised controlled trial on whether a participatory Ergonomics intervention could prevent musculoskeletal disorders. Occup Environ Med 2008;65:849-56.

40 Helewa A, Goldsmith $\mathrm{CH}$, Lee $\mathrm{P}$, et al. Does strengthening the abdominal muscles prevent low back pain--a randomized controlled trial. J Rheumatol 1999;26:1808-15

41 Hill JJ, Keating JL. Daily exercises and education for preventing low back pain in children: cluster randomized controlled trial. Phys Ther 2015;95:507-16.
42 Horneij E, Hemborg B, Jensen I, et al. No significant differences between intervention programmes on neck, shoulder and low back pain: a prospective randomized study among home-care personnel. J Rehabil Med 2001;33:170-6.

43 IJzelenberg $\mathrm{H}$, Meerding W-J, Burdorf A. Effectiveness of a back pain prevention program: a cluster randomized controlled trial in an occupational setting. Spine 2007:32:711-9.

44 Kraus JF, Schaffer KB, Rice T, et al. A field trial of back belts to reduce the incidence of acute low back injuries in New York City home attendants. Int J Occup Environ Health 2002;8:97-104.

45 Larsen K, Weidich F, Leboeuf-Yde C. Can custom-made biomechanic shoe orthoses prevent problems in the back and lower extremities? A randomized controlled intervention trial of 146 military conscripts. J Manipulative Physiol Ther 2002;25:326-31.

46 Larsen $\mathrm{K}$, Weidick F, Leboeuf-Yde C. Can passive prone extensions of the back prevent back problems? A randomized, controlled intervention trial of 314 military conscripts. Spine 2002;27:2747-52.

47 Lavender SA, Lorenz EP, Andersson GBJ. Can a new behaviorally oriented training process to improve lifting technique prevent occupationally related back injuries due to lifting? Spine 2007;32:487-94.

48 Lønn JH, Glomsrød B, Soukup MG, et al. Active back school: prophylactic management for low back pain. A randomized, controlled, 1-year follow-up study. Spine 1999;24:865-71.

49 Mattila VM, Sillanpää P, Salo T, et al. Orthotic insoles do not prevent physical stressinduced low back pain. Eur Spine J 2011;20:100-4

50 Méndez FJ, Gómez-Conesa A. Postural hygiene program to prevent low back pain. Spine 2001;26:1280-6.

51 Milgrom C, Finestone A, Lubovsky 0 , et al. A controlled randomized study of the effect of training with orthoses on the incidence of weight bearing induced back pain among infantry recruits. Spine 2005;30:272-5.

52 Moore C, Ceridan E, Schonard C, et al. Prevention of low back pain in sedentary healthy workers: a pilot study. Am J Med Sci 2012;344:90-5.

53 Roussel NA, Kos D, Demeure I, et al. Effect of a multidisciplinary program for the prevention of low back pain in hospital employees: a randomized controlled trial. J Back Musculoskelet Rehabil 2015;28:539-49.

54 Schwellnus MP, Jordaan G, Noakes TD. Prevention of common overuse injuries by the use of shock absorbing insoles. A prospective study. Am J Sports Med 1990;18:636-41.

55 Sihawong R, Janwantanakul P, Jiamjarasrangsi W. A prospective, cluster-randomized controlled trial of exercise program to prevent low back pain in office workers. Eur Spine J 2014:23:786-93.

56 Soukup MG, Glomsröd B, Lönn JH, et al. The effect of a Mensendieck exercise program as secondary prophylaxis for recurrent low back pain. A randomized, controlled trial with 12-month follow-up. Spine 1999;24:1585-92

57 Soukup MG, LÖnn J, GlomsrÖd B, et al. Exercises and education as secondary prevention for recurrent low back pain. Physiother. Res. Int. 2001;6:27-39.

58 Suni JH, Taanila $\mathrm{H}$, Mattila VM, et al. Neuromuscular exercise and counseling decrease absenteeism due to low back pain in young conscripts: a randomized, populationbased primary prevention study. Spine 2013:38:375-84.

59 van Poppel MN, Koes BW, van der Ploeg T, et al. Lumbar supports and education for the prevention of low back pain in industry: a randomized controlled trial. JAMA 1998:279:1789-94.

60 Warming S, Ebbeh $\oslash j \mathrm{NE}$, Wiese N, et al. Little effect of transfer technique instruction and physical fitness training in reducing low back pain among nurses: a cluster randomised intervention study. Ergonomics 2008:51:1530-48.

61 Weber M, Cedraschi C, Roux E, et al. A prospective controlled study of low back school in the general population. Rheumatology 1996;35:178-83.

62 Yu W, Yu ITS, Wang $X$, et al. Effectiveness of participatory training for prevention of musculoskeletal disorders: a randomized controlled trial. Int Arch Occup Environ Health 2013:86:431-40.

63 Danquah IH, Kloster S, Holtermann A, et al. Effects on musculoskeletal pain from "Take a Stand!" - a cluster-randomized controlled trial reducing sitting time among office workers. Scand J Work Environ Health 2017;43:350-7.

64 Gram B, Holtermann A, Bültmann U, et al. Does an exercise intervention improving aerobic capacity among construction workers also improve musculoskeletal pain, work ability, productivity, perceived physical exertion, and sick leave?: a randomized controlled trial. J Occup Environ Med 2012;54:1520-6.

65 Pillastrini P, Mugnai R, Bertozzi L, et al. Effectiveness of an at-work exercise program in the prevention and management of neck and low back complaints in nursery school teachers. Ind Health 2009; 47:349-54.

66 Gundewall B, Liljeqvist M, Hansson T. Primary prevention of back symptoms and absence from work. A prospective randomized study among hospital employees. Spine 1993:18:587-94

67 Kellett KM, Kellett DA, Nordholm LA. Effects of an exercise program on sick leave due to back pain. Phys Ther 1991;71:283-91.

68 Soukup MG, Glomsröd B, Lönn JH, et al. The effect of a Mensendieck exercise program as secondary prophylaxis for recurrent low back pain. A randomized, controlled trial with 12-month follow-up. Spine 1999;24:1585-91. 
69 Bigos SJ, Holland J, Holland C, et al. High-Quality controlled trials on preventing episodes of back problems: systematic literature review in working-age adults. Spine J 2009;9:147-68.

70 Verbeek J, Martimo KP, Karppinen J, et al. Manual material handling advice and assistive devices for preventing and treating back pain in workers: a Cochrane systematic review. Occup Environ Med 2012;69:79-80.

71 Jellema P, van Tulder MW, van Poppel MN, et al. Lumbar supports for prevention and treatment of low back pain: a systematic review within the framework of the Cochrane back review group. Spine 2001;26:377-86.
72 Saragiotto BT, Latimer J. Prevention of low back pain (PEDro synthesis). Br J Sports Med 2016;50:1345.

73 Shiri R, Coggon D, Falah-Hassani K. Exercise for the prevention of low back pain: systematic review and meta-analysis of controlled trials. Am J Epidemiol 2018;187:1093-101.

74 Steffens D, Maher CG, Pereira LSM, et al. Prevention of low back pain: a systematic review and meta-analysis. JAMA Intern Med 2016;176:199-208. 